\title{
Residência multiprofissional em saúde da família: vivencias de residentes de enfermagem
}

\author{
Marcelo da Silva Alves, D.Sc.*, Andyara do Carmo Pinto Coelho Paiva**, Flávia Alves Condé Pires Guelber**, \\ Priscila Araújo Rocha**, Anna Maria de Oliveira Salimena, D.Sc.***
}

* Enfermeiro, Professor da Faculdade de Enfermagem da Universidade Federal de Juiz de Fora, Coordenador do Programa de Residência Multiprofissional em Saúde da Familia, **Enfermeira, Pós-graduada do Programa de Residência Multiprofissional em Saúde da Familia, Mestranda do PPG-Mestrado em Enfermagem da Universidade Federal de Juiz de Fora, ***Enfermeira, Professora do Departamento Enfermagem Aplicada da Faculdade de Enfermagem da Universidade Federal de Juiz de Fora, Coordenadora do PPG-Mestrado em Enfermagem da Universidade Federal de Juiz de Fora

\section{Resumo}

Objetivo: Descrever a vivência de residentes do Programa de Residência Multiprofissional em Saúde da Família no serviço. Material e métodos: Trata-se de um relato de experiência acerca das atividades desenvolvidas em uma Unidade de Atenção Primária à Saúde por enfermeiras egressas do Programa de Residência Multiprofissional em Saúde da Família da Universidade Federal de Juiz de Fora. Resultados: As atividades desenvolvidas no programa como processo de territorialização, curso introdutório com questôes pertinentes a saúde da família, acolhimento, reunióes de equipe e consultas de enfermagem permitiram o preenchimento das lacunas provenientes da Graduação e a formação de profissionais atualizados e comprometidos com o cuidado. A residência promove uma formaçáo voltada para o mundo do trabalho, preparando o enfermeiro para reconhecer as necessidades de saúde da população. Conclusão: A experiência da residência possibilitou o crescimento e o enriquecimento profissional, bem como contribuiu para a formação de especialistas com vivência na realidade de uma Unidade de Saúde, com todas suas especificidades e complexidade.

Palavras-chave: atenção à saúde, saúde da família, educação em enfermagem, internato não médico.

\section{Abstract \\ Multiprofessional residence in family health: experience of resident nurses}

Objective: To describe the experiences of residents of Multiprofessional Residency Program in Family Health at work. Method: This was an experience report concerning postgraduate nurse activities in one Primary Health Care Unit of Multidisciplinary Residency Program in Family Health at the Federal University of Juiz de Fora. Results: The activities developed within the program as territorialization process, introductory course with issues relevant to family health, acceptance, team meetings and nursing consultations allowed the filling in the gaps coming from graduation and the formation of updated professionals and committed to care. The residence promotes oriented training for the world of 
work, preparing nurse to recognize the health needs of the population. Conclusion: The experience of residence allowed professional growth and enrichment, as well as contributed to the training of specialists with experience in the reality of a Health Unit, with all its specificities and complexities.

Key-words: health care, family health, Education Nursing, internship nonmedical.

\section{Resumen}

\section{Residencia multiprofesional en salud familiar: experiencias de residente de enfermería}

Objetivo: Describir las experiencias de los residentes del Programa de Residencia multidisciplinario en el servicio de salud familiar. Métodos: Se trata de relato de experiencia sobre las actividades de la unidad de Atención Primaria de Salud en el Programa de Residencia Multidisciplinaria de Salud Familiar de la Universidad Federal de Juiz de Fora. Resultados: Las actividades en el programa como proceso de territorialización, curso de introducción a las cuestiones pertinentes a la atención de salud de la familia, reuniones de personal y consultas de enfermería permitieron rellenar lagunas provenientes de la graduación y la capacitación de profesionales actualizados y comprometidos con la atención. La residencia promueve la formación orientada al mundo del trabajo, preparando el enfermero para reconocer las necesidades de salud de la población. Conclusión: La experiencia de la residencia permitió el crecimiento profesional y enriquecimiento, así como contribuyó a la formación de especialistas con experiencia en la realidad de una Unidad de Salud, con todas sus especificidades y complejidades.

Palabras-clave: atención a la salud, salud de la familia, educación en enfermería, internado no médico.

\section{Introdução}

A Estratégia em Saúde da Família (ESF) foi implantada no Sistema Único de Saúde (SUS) no Brasil em 1990 como forma de reorientação da Atenção Primária e, desde entáo, enfrenta desafios ao se deparar com poucos profissionais qualificados, considerando a complexidade do processo saúde doença. Nesse contexto, o Ministério da Saúde (MS) tem apoiado a formação de especialistas nesta área com programas de pós-graduação lato-sensu na modalidade de residência em saúde da família, que tem por objetivo o treinamento em serviço, articulando conhecimentos teóricos e a prática, qualificando profissionais a partir da vivência no serviço e a formaçáo crítico-reflexivo [1].

Apesar do desafio em transformar a formação e as práticas na área da saúde, por implicar a mudanças de paradigmas já estabelecidos nos serviços e nas instituiçôes de ensino, acredita-se que com o diálogo e a aproximação da realidade da população será possível construir uma nova forma de trabalho em saúde, baseado na qualidade, resolubilidade e equidade [2].

Em um município da Zona da Mata Mineira, o Programa de Residência Multiprofissional em Saúde da Família foi implantado em setembro de 2002 em um momento de expansão e consolidação da Estratégia da Saúde da Família, através da integração entre a Universidade Federal de Juiz de Fora (UFJF) e a rede de assistência local e regional. Sua formação metodológica é norteada pela concepção pedagógica fundamentada no diálogo, na participação e na problematizaçáo da realidade [3].

Fazem parte, deste programa, residentes de enfermagem, medicina e assistência social, além de seus respectivos preceptores de serviço que tem como função assegurar o conhecimento técnico-científico, acompanhar e supervisionar o desempenho dos residentes, auxiliar no planejamento da execuçáo dos objetivos, diretrizes e metas para atender as especificidades de cada Unidade de Atenção Primária à Saúde (UAPS), promover discussões teóricas e práticas e ajudar na resolução de açôes programadas e de emergência [1] e de preceptores acadêmicos que oferecem aulas periódicas com textos e temas referentes ao trabalho do enfermeiro e discussóes da prática, levando à reflexão crítica [4].

O Programa tem como principal objetivo o trabalho focado na realidade local aplicando conhecimento científico, popular e desenvolver habilidades que possibilitem a realização de atendimentos individuais de forma integral, não apenas focadas no indivíduo, mas em seu meio 
familiar, cultural e social de forma multiprofissional e interdisciplinar.

Sabe-se que o conhecimento clínico é importante para os profissionais da área da saúde, entretanto para atender a proposta da residência, outros assuntos devem ser colocados em pauta, como o processo de humanização do trabalho, as estratégias de comunicação e a educação em saúde, o que permitirá aos residentes desenvolverem um olhar ampliado em saúde [5].

Acredita-se que é a partir da vivência no serviço, permeada por um suporte pedagógico direcionado para as necessidades da comunidade, que se constrói uma formação técnica e humanística do profissional, considerando que as situaçóes vivenciadas no contexto do serviço exigem açóes que ultrapassam o conhecimento puramente científico e clínico [6].

Conscientes da importância dessas reflexóes acerca da reorientaçáo do modelo assistencial, a fim de situar o papel do profissional nessa nova forma de atuar na saúde, e da importância do aperfeiçoamento profissional para a inserção deste no PSF, tornou-se objetivo deste artigo descrever a vivência de residentes do Programa de Residência Multiprofissional em Saúde da Família no serviço.

\section{Material e métodos}

Estudo descritivo de abordagem qualitativa na modalidade de relato de experiência, que emergiu da vivência do cotidiano da prática profissional a partir das experiências [7] de três enfermeiras egressas do Programa de Residência Multiprofissional em Saúde da Família da Universidade Federal de Juiz de Fora, em uma Unidade de Atenção Primária em Saúde num município do interior de Minas Gerais.

Partindo de pesquisa realizada sobre atividades desenvolvidas durante o período da residência, aprovada pelo Comitê de Ética em Pesquisa da Universidade Federal de Juiz de Fora, segundo parecer $n^{\circ} 170 / 2011$, sentimos a necessidade de divulgar as vivências do processo de trabalho e suas implicaçóes, por considerarmos a proposta da residência enriquecedora para o conhecimento e a prática profissional.

Então, a partir das nossas vivências como residentes, destacamos algumas atividades experienciadas, apoiando tais relatos e reflexóes nos artigos científicos provenientes das revistas indexadas e de informaçóes do Ministério da Saúde.

\section{Resultados e discussão}

As atividades no Programa iniciaram-se com a apresentação do universo da Saúde da Família às residentes, debatendo aspectos fundamentais das políticas de saúde no Sistema Único de Saúde (SUS), integrando o olhar das diversas profissóes que compóem a residência, no que foi chamado de Curso Introdutório ministrado por profissionais experientes na área de Saúde Pública.

Também tivemos a oportunidade de debater, de forma mais aprofundada, as políticas desenvolvidas pelo Ministério da Saúde (MS) quanto à Saúde da Mulher, do Homem, do Idoso, da Criança e do adolescente e da complexidade da Atenção Primária dentro dos demais níveis de atenção. Este curso foi de grande importância para embasar a nossa prática e nos inserir na realidade do serviço.

Estudo já realizado, com preceptores e profissionais do serviço de um programa de residência, ressalta que é fundamental para um bom desempenho no processo laboral ter conhecimento sobre "as políticas públicas, processo saúde-doença, atenção primária, interdisciplinaridade, práticas de saúde coletiva, rede de referência e contra-referência, princípios e estratégias organizacionais da ESF" [2:824].

Posteriormente, em um trabalho integrado com o Serviço Social, realizamos o Processo de Territorialização com o auxílio das Agentes Comunitárias de Saúde (ACS). Esse processo exige responsabilidade da Unidade de Saúde com as questóes que envolvem a qualidade de vida dos indivíduos, famílias e comunidade, além do reconhecimento das especificidades locorregionais [2].

A partir de então, com os conhecimentos adquiridos na Graduação e reflexóes no Curso Introdutório, percebemos as necessidades gerais da comunidade e constatamos que um trabalho específico deveria ser realizado para atender essas demandas, com base nos princípios do SUS. Ressaltamos que a Territorializaçáo realizada por uma equipe multiprofissional contribui para que visóes diferentes se somem para formular um diagnóstico amplo e detalhado da área.

Tal atividade nos permitiu conhecer a rede institucional e as possíveis alternativas de recursos sociais; desenvolver de forma crítica novas técnicas de trabalho, de acordo com a realidade local, tanto em nível individual desenvolvido dentro da 
Unidade de Atenção Primária à Saúde (UAPS) ou nas visitas domiciliares, como no nível coletivo.

Neste contexto, a interação com outra categoria profissional ocorre a partir do compromisso em pensar o cuidado que vem sendo ofertado nos serviços de saúde e ressignificar essa prática através do compartilhamento de diversos saberes dos sujeitos envolvidos [3].

Umas das atividades das equipes na Estratégia de Saúde da Família (ESF) é o acolhimento. Essa atividade favorece a construção de uma relação de confiança e compromisso dos usuários com as equipes e os serviços, contribuindo para a legitimação do Sistema Público de Saúde [8].

Observamos, em nossa prática, que o acolhimento nesta Unidade é bem desenvolvido considerando que o processo de trabalho é organizado de modo que todos os profissionais participem dessa atividade de forma a construir o vínculo com o usuário. Acreditamos que esse contato seja essencial para que se possa identificar suas necessidades e sermos reconhecidos como os profissionais da equipe. Além disso, a interação com envolvimento de toda equipe, de forma contínua, favorece as mudanças dos indicadores de saúde da população e assim possibilita uma melhor qualidade de vida [2].

Constatamos, ao assumir o serviço, que há lacunas na Graduação, o que gera ansiedade e insegurança ao exercer as atividades de rotina. Acreditamos que as bases teóricas de enfermagem ainda são deficientes na academia, o que contribui para não reconhecermos o verdadeiro papel do enfermeiro na ESF, confundido muitas vezes com atividades de outros profissionais.

Essa lacuna é preenchida pela proposta de formação a partir da aprendizagem vivenciada na realidade dos serviços nas Unidades de Saúde da Família [2], utilizando para isso uma reflexão crítica, análise, síntese e aplicação de conceitos voltados para efetiva construção do conhecimento [9].

Realizamos consultas de enfermagem com atendimento à saúde da mulher, da criança e do adulto seguindo protocolos da Unidade e impressos próprios elaborados por residentes egressos, que auxiliam numa abordagem direcionada e acompanhada pelo processo de enfermagem. Ao iniciarmos as consultas, sentimos certa insegurança ao abordarmos o usuário e por não conseguirmos atender a todas as demandas que ele trazia. Ressaltamos que a Atenção Primária é muitas vezes marcada por número insuficiente de profissionais, recaindo "sobre o enfermeiro a responsabilidade de suprir a ausência de outros profissionais" [9].

Com o passar do tempo, delimitamos melhor quais seriam as nossas funçóes e o propósito dessa consulta que é de promoção, prevenção e recuperação da saúde, tendo como enfoque a Educação em Saúde. Pensamos no cuidado considerando seus determinantes históricos, sociais e políticos, buscando intervir de forma a proporcionar autonomia dos sujeitos [4].

A prática clínica voltada para a prescrição e o tratamento de doenças tem um papel importante no contexto do cuidado aos indivíduos que adoecem, porém é fundamental que seja atrelada a uma visão ampliada de saúde, de maneira que incorpore uma dimensão humanística e integral no processo saúde-doença [2].

Sendo assim, emerge a importância das açóes de Promoção da Saúde, como reorientação do modelo assistencial, com a intencionalidade de utilizá-la não apenas para a prevenção das doenças, mas como instrumento de conscientizaçáo e enfrentamento das vulnerabilidades [2].

Acreditamos que a participação em grupos de estudos, aulas teóricas com a preceptoria acadêmica e discussóes de casos clínicos possibilitaram nosso crescimento e enriquecimento profissional, através de uma reflexáo crítica, pautada em marcos teórico e estudos científicos atualizados, próprios da nossa profissão.

A residência promove uma formação voltada para o mundo do trabalho preparando o profissional para reconhecer as necessidades de saúde da população e propondo resoluções aos problemas de saúde, tendo em vista os determinantes e os condicionantes que enfrentam no cotidiano laboral [2].

Como enfermeiras egressas, estamos em processo de construçáo de um novo modo de agir em saúde coletiva, identificando nossos espaços e revelando os benefícios que a populaçáo pode usufruir através desse novo olhar, tendo como prioridade atividades de promoção e prevenção da saúde. Sendo assim, podemos afirmar que a Residência Multiprofissional em Saúde da Família foi uma etapa importante para a formação de uma identidade profissional e nos possibilitou uma prática assistencial crítica e reflexiva.

O Programa de Residência permite um preparo técnico-científico especializado, com capaci- 
dade de distinguir prioridades, adquirir segurança pessoal e profissional na execução das atividades práticas, qualificar o atendimento na instituição e liderar a equipe, condiçóes que favorecem a realização profissional [4].

A partir dessa vivência, percebemos que a residência vem permitindo ao enfermeiro recém-formado, a construçáo de competências aliadas à aquisição de conhecimentos, desenvolvimento de habilidades e construção de atitudes. O preenchimento das lacunas provenientes da Graduação se constitui em uns dos pontos mais importantes, uma vez que permite aos residentes sanar essas dificuldades e desenvolver sua prática pautada no modelo vigente sob a orientação dos preceptores e tutores, os quais sáo profissionais atualizados e comprometidos com o cuidado, ensino, pesquisa e extensão.

Profissionais qualificados são essenciais para elevar o nível de saúde da população. Para isso, é preciso que o enfermeiro detenha um conjunto de conhecimentos científicos e práticos a fim de oferecer uma assistência segura e resolutiva [4].

\section{Conclusão}

A experiência de vivenciar a Residência Multiprofissional em Saúde da Família contribuiu para nossa formação como especialistas, com vivência na realidade de uma Unidade de Atenção Primária à Saúde com todas suas especificidades e complexidades, não apenas nas funçóes que requerem habilidades técnicas, mas no desenvolvimento de uma postura ética profissional, aprendendo a criar o vínculo com o indivíduo e suas famílias, para que se possa estabelecer uma relação de confiança e comprometimento.

Sendo assim, reafirma-se que a articulação entre Estratégia Saúde da Família e Residência em Saúde da Família resulta em inúmeros benefícios, pois a grande transformação proposta pelo então modelo de atenção está calcada na participação intersetorial para que ocorra um melhor desenvolvimento das atividades e do processo de trabalho.
O processo de formação do profissional de enfermagem, na atualidade, é um grande desafio, considerando a necessidade de formar profissionais com competência técnica e política, com conhecimento, raciocínio, percepção e sensibilidade para as questóes individuais e coletivas, devendo estar preparados para atuar em contextos que envolvem incertezas e complexidade. Assim, faz-se necessário ter enfermeiros comprometidos com os problemas de saúde da comunidade, náo perdendo a perspectiva da integralidade da atençáo, da equidade, da eficiência e da eficácia.

\section{Referências}

1. Brasil, Ministério da Saúde. Secretaria de atenção à saúde. Núcleo técnico da política nacional de humanização. Acolhimento nas práticas de produção de saúde. 2aed. Brasília: Ministério da Saúde; 2006.

2. Nascimento DDG, Oliveira MAC. Competências profissionais e o processo de formação na residência multiprofissional em saúde da família. Saúde Soc 2010;19(4):814-27.

3. Freitas CHSM. Residência multiprofissional em saúde da família e comunidade: experiência, avanços, desafios. Pesqui Bras Odontopediatria Clín Integr 2012;12(2):153-4.

4. Carbogim FC, Santos KB, Alves MS, Silva GA. Residência em Enfermagem: a experiência de Juiz de Fora do ponto de vista dos residentes. Rev APS 2010;13(2):245-9.

5. Ferreira SR, Olschowsky A. Residência integrada em saúde: a interação entre as diferentes áreas de conhecimento. Rev Gaúch Enferm 2010;30(1):106-12.

6. Nascimento DDG, Quevedo MP. Aprender fazendo: consideraçóes sobre a residência multiprofissional em saúde da família na qualificação de profissionais da saúde. In: Bourget MMM (org.). Estratégia Saúde da Família: a experiência da equipe de reabilitação. São Paulo: Martinari; 2008. p.43-59.

7. Minayo MCS, eds. Pesquisa social: teoria, método e criatividade. Rio de Janeiro: Vozes; 2007.

8. Ministério da Saúde. Secretaria de gestão do trabalho e educação na saúde. Departamento de gestão da educação na saúde. Residência Multiprofissional em saúde: experiências, avanços e desafios. Brasília: Ministério da Saúde; 2006.

9. Caçador BS, Lopes FN, Pacheco LC, Alves MS, Salimena AMO. O enfermeiro na estratégia da saúde da família: percepção do usuário. HU Rev 2012;37(3):331-8. 